\title{
A rational approach to long term care: comparing the independent living model with agency-based care for persons with high spinal cord injuries
}

\author{
Jane Mattson-Prince
}

6 Ocean View Drive, Stamford, Connecticut 06902, USA

\begin{abstract}
Two groups of individuals with high level tetraplegia $(\mathrm{C} 1-4)$ were compared with respect to the model of personal care assistance used. The study was undertaken to determine whether a finite population with severe disability had differences in health status, costs and perceived quality of life, relative to whether they used agencies for their care, or hired, trained and reimbursed care givers independently. A survey, which included demographics as well as portions of RAND-36, LSI-A, PIP, PASI and CHART was used. Telephone interviews were held with 29 individuals who received their care through an agency and 42 who managed care independently. Chi square, 't'-tests, and multiple regression analysis were used to control for potentially confounding group differences. The self-managed group demonstrated significantly better health outcomes, with fewer re-hospitalizations for preventable complications. They experienced better life satisfaction and significantly lower costs. Although those who used an independent model of care-giving received significantly more hours of paid assistance, the average annual cost of care was significantly lower for each individual. In addition to reducing the financial burden on the individual and society, self-managed care seemed to diminish the emotional burden borne by these individuals.
\end{abstract}

Keywords: high spinal cord injury ('SCI'); quality of life; health status; independent living

\section{Introduction}

For persons with high SCI in the United States, personal assistance has followed a medically-supervised model, in which reimbursement has flowed to a home health agency from a third party payor. The cost of using agencies astronomically raises aggregate annual costs. Publicly-funded health care entitlement programs have limited funding to adequately meet increasing costs linked to longer survival of extremely disabled persons. Innovative policies have long been needed to implement cost-effective long-term care plans to serve this population.

Two models of long-term care are analyzed. In the agency-based model, the recipient of services is described as a 'patient' who assumes a sick role and is excused from everyday activitiy. ${ }^{1}$ Care-giving decisions are relinquished to a healthcare professional. $^{2}$ As a result of a lack of awareness as to what personal assistance encompasses, many people who require services have been unable to receive them because of inadequate financial resources. The result has been that, in the absence of one-on-one personal assistance, independent living has been unattainable for over 3 million Americans with disabilities. ${ }^{3}$

Nosek $^{4-7}$ and Litvak ${ }^{8}$ have studied models of care throughout the world, but have not ascertained whether there is any significant correlation between consumer control and quality of personal assistance attributable to the independent living model, compared to agency-based care, measured in terms of fewer preventable health problems, cost manageability and self-reported quality of life.

The independent living model was initiated by working age persons with disabilities who sought removal of both environmental and social barriers to access in their communities. ${ }^{9,11}$ The individual with a disability is considered an active recipient of services. $\mathrm{He}$ or she recruits, selects, manages, directs and reimburses his/her care providers. In many states, the independent living model is favored under Title XIX and XX of the Social Security Act.

There is a third model of informal support in which the family provides most of the care for the individual. However, persons with high SCI typically require a level of assistance that warrants a paid source to meet basic needs.

Optimum care-giving depends on the interpersonal relationship between the client and the care-giver. For a person who has sustained high SCI, the illness trajectory can be skewed when there is a medicallysupervised model of care-giving and, as users of care services maneuver through the maze of service programs in order to achieve health maintenance, they may become locked within a 'sickness model'. ${ }^{1,3,13}$ As a result, care-giving itself may influence how the person with SCI begins to view him or 
herself ${ }^{10,11}$ and independent living may not be pursued as actively. ${ }^{12-14}$ Thus, a clear distinction between perceived and real needs is crucial. ${ }^{15,16}$

Perception of illness as well as the actual amount of support received affects the degree of disability that follows the onset of impairment. ${ }^{17}$ As a result of care giving, 'external' personalities (persons who were passive prior to their injury) may undergo a change during or after rehabilitation. Studies have shown that similarities in levels of life satisfaction for individuals with SCI and persons of similar age without SCI were greater than anticipated. ${ }^{18}$

The outlook for persons with SCI has improved significantly in the last decade; ${ }^{19}$ individuals may now be treated with gluco-cortico steroids and they may experience improved recovery with better functional outcome. Greater technological assistance provides a better chance for independent living. Follow-up is necessary to help persons deal with medical, functional and psychosocial issues relating to the aging process and to life in general. ${ }^{9,20,21}$

According to data collected at the National Spinal Cord Injury Stastistical Center ('NSCISC') at the University of Alabama in Birmingham, individuals who are involved with a model systems program (established in the 1970's by the National Institute of Rehabilitation and Research) experience great functional ability at discharge. ${ }^{10}$ If persons with severe disabilities do not have adequate personal care assistance in order to perform activities of daily living and maintain their health effectively after discharge, rehabilitation itself may be futile. ${ }^{19}$ Nosek suggests that there has not been adequate development of formal systems for personal assistance service delivery. ${ }^{6}$ Ways in which persons with SCI obtain personal assistance remain complicated and involve relationships with families, friends and neighbors, as well as formal service providers, employers and agencies. To date, no study has determined the most effective mix of formal and informal care. ${ }^{22}$ Medicaid Waivers, Social Service Block Grants, Veteran's Administration Aid and Attendant Allowance, and commercial insurance companies have created a maze of inadequate and often overlapping services.

Independent living is negatively impacted by frequent re-hospitalizations following SCI. ${ }^{23}$ The three primary medical problems considered to be preventable are: urinary tract infections, pneumonia and decubitus ulcers. 7,9

Persons who had sustained high SCI were chosen for this project because the onset of their disability was clearly marked in time and they often require paid care-giving for survival. A formal research model specifying socio-demographic, disability-related and outcome measures has been developed. The independent variable is model of care. Health status, quality of life, locus of control and cost were hypothesized to be dependent upon receiving paid care, either through agencies or the independent living model. Potentially confounding variables were income, number of years since onset of disability, hours of paid care and employment status. Telephone interviews took place during August and September of 1993.

\section{Method}

A questionnaire regarding frequency of hospitalizations for skin lesions, bladder infections or respiratory problems was administered to ten persons who had sustained high cervical SCI. Individuals were interviewed in their homes for this pre-test. Four were referred by the Boston Center for Independent Living; the remaining six came from cases followed directly by this author. Only one of these ten individuals had significant hospital recidivism; this individual was using an agency. The remaining nine were using the independent living model and had not been hospitalized in the preceding 5 years.

Seventy-one individuals with high cervical SCI who had been at Craig Rehabilitation Hospital in Englewood, Colorado were then interviewed by telephone. Many were included in the National Spinal Cord Data Bank or in a collaborative study of high quadriplegia completed in 1985 by Craig Hospital, Santa Clara (California) Valley Medical Center and The Institute for Rehabilitation and Research in Houston.

\section{Design}

The questionnaire contains significant portions of the RAND-36, LSI-A, CHART, PASI and PIP as well as a demographic section. Several $t$ tests were used to determine whether there were statistical differences between groups; there were none.

The RAND-36 provides a generic measure of patient function and well-being. A high score on the RAND-36 shows a more favorable health status. Ten questions in the Rand were not utilized in this survey because they implied physical functioning below the neck and would be demeaning.

The LSI-A was developed from an extensive 5-year study of relatively healthy, middle-class, urban individuals from Kansas City and measures current satisfaction against life satisfaction prior to the onset of disability.

CHART is used to measure an individual's level of physical independence, mobility, occupation, social integration and economic self-sufficiency.

PASI evaluates the level of satisfaction an individual has with his or her life as a result of the care being received. During development, PASI was administered to 661 persons with mixed disabilities. Sixteen questions on the PASI were scored on a fivepoint Likert scale.

PIP evaluates independence-orientation in terms of internal and external locus of control, using the following components of independence: perceived control over one's life; psychological self-reliance; physical functioning; and environmental factors. In order to eliminate redundancy, only the first two parts 
of PIP were administered in this study. The first part of PIP asks the respondent to think of his/her level of control over an area of life. Questions are posed to assess control of material comforts, participation in recreation, preservation of close friendships, adequacy of health and personal safety, closeness of relationship with spouse, pursuit of leisure activities (i.e., reading, socializing), work, family relationships, and the ability to learn. The second section of PIP contains 34 items regarding expenses, residence, independence, cost of care, gender, and participation in life.

\section{Analysis (Table 1)}

Socio-demographic variables included age, gender, race, education, marital status, income, living situation (alone or with others), reliance on family, and employment status. Variation between the models was not significant using ANOVA.

Both race and gender were subject to chi square analysis; neither was significantly different, as this

Table 1 Analysis of group differences

\begin{tabular}{|c|c|c|}
\hline $\begin{array}{l}\text { Socio-demographic } \\
\text { variables }\end{array}$ & $\begin{array}{l}\text { Agency-provider } \\
\text { model }(\mathrm{n}=29)\end{array}$ & $\begin{array}{l}\text { Self-managed } \\
\text { model }(\mathrm{n}=42)\end{array}$ \\
\hline Mean Age & $35.3 \mathrm{y}$ & $37.1 \mathrm{y}$ \\
\hline$\%$ Male & 93.1 (27 persons) & 95.2 (40 persons) \\
\hline$\%$ Ethnic Minority & 10.3 (3 persons) & 4.8 (2 persons) \\
\hline$\%$ Married & 27.6 (8 persons) & 31 (13 persons) \\
\hline $\begin{array}{l}\% \text { with Education } \\
\text { beyond high } \\
\text { school }\end{array}$ & 69 (20 persons) & 59.5 ( 25 persons $)$ \\
\hline $\begin{array}{l}\% \text { Living with } \\
\text { others }\end{array}$ & 93.1 (27 persons) & 81 (34 persons) \\
\hline$\%$ Working $^{\mathrm{b}}$ & 20.3 (3 persons) & 31 (13 persons) \\
\hline $\begin{array}{l}\text { Mean total annual } \\
\text { income }^{\mathrm{b}}\end{array}$ & $\$ 21,495$ & $\$ 35,036$ \\
\hline $\begin{array}{l}\text { Mean productive } \\
\text { h/week } \\
\text { (work + volunteer }+ \\
\text { School) }\end{array}$ & $12.3 \mathrm{~h}$ & $15.6 \mathrm{~h}$ \\
\hline \multicolumn{3}{|l|}{ Injury-related variables } \\
\hline Mean age at injury & $27.4 \mathrm{y}$ & $25.6 \mathrm{y}$ \\
\hline $\begin{array}{l}\text { Mean years since } \\
\text { onset }^{\text {b }}\end{array}$ & $7.9 \mathrm{y}$ & $11.48 \mathrm{y}$ \\
\hline $\begin{array}{l}\% \text { Full-time ventilator } \\
\text { use }\end{array}$ & 3.4 (1 person) & 7.1 (3 persons) \\
\hline \multicolumn{3}{|l|}{ Service delivery variable } \\
\hline Hours paid care ${ }^{\mathrm{b}}$ & $8.1 \mathrm{~h}$ & $14.5 \mathrm{~h}$ \\
\hline Hours unpaid care & $7.7 \mathrm{~h}$ & $4.3 \mathrm{~h}$ \\
\hline Total hours care & $15.8 \mathrm{~h}$ & $18.8 \mathrm{~h}$ \\
\hline $\begin{array}{l}\text { Ratio of skilled care } \\
\text { of total care }\end{array}$ & $10.1 \%$ & $7.9 \%$ \\
\hline $\begin{array}{l}\text { Ratio of paid to total } \\
\text { care }\end{array}$ & $51.3 \%$ & $77.1 \%$ \\
\hline $\begin{array}{l}\% \text { Funded by } \\
\text { government } \\
\text { Entitlement } \\
\text { programs }\end{array}$ & $65.6 \%$ & $6.3 \%$ \\
\hline
\end{tabular}

study predominantly involved male Caucasians. On chi square analysis, there was no significant difference in regard to marital status. However, income in this study was highly skewed. In order to determine income, the cost of non-reimbursed care was subtracted from stated income. On ANOVA, there was a significant difference between the models $(f(1,69)=5.01, P<0.01)$. Mean income was $\$ 36.036$ for individuals using the independent living model and \$21.495 for individuals using the agency model.

Family involvement in care-giving was the rule rather than the exception. Twenty-eight persons $(67 \%)$ in the independent living model relied on family or significant others for part of their care; fourteen persons $(33 \%)$ did not. This was not significantly different in the agency model, where 22 persons $(76 \%)$ relied on family for some care-giving and seven persons $(24 \%)$ did not.

Individuals who had greater control of their care were more apt to be working. Sixteen persons $(22.5 \%)$ out of the 71 in this study were working, 55 persons $(77.5 \%)$ were not. On chi square analysis there was a significant difference between the models in regard to employment. For those in the agency model, three persons $(10.3 \%)$ were working while $26(89.7 \%)$ were not. By contrast, 13 persons $(31 \%)$ whose care complies with the independent living model were working and $29(69 \%)$ were not.

\section{Service delivery variables}

In the medically-supervised agency model, 19 persons $(60 \%)$ had Medicaid sponsors; one $(3 \%)$ had health insurance; six $(21 \%)$ had automobile or Worker's Compensation insurance; and three $(10 \%)$ paid privately for care through savings or settlements. In the independent living model, 11 individuals (27\%) had Medicaid sponsors; $13(33 \%)$ had health insurance; seven (15\%) had automobile or Worker's Compensation insurance; and $11(27 \%)$ were paying for their own care. On a chi square analysis there was a significant relationship between payor and model. Of those using agencies, $66 \%$ had government sponsors; in the independent living model, only $27 \%$ had government payors.

Of the 42 persons in the independent living model, 19 had begun their care in this model; 23 (55\%) had switched to it. Of the 29 persons in the agency care model, $17(50 \%)$ had begun in this model; $12(41 \%)$ switched to it.

Total hours of care were similar between the models when not accounting for paid or unpaid care. The ratio of unpaid hours to paid hours was much greater for persons in the agency model.

\section{Injury variables}

Persons in the agency model generally had lower spinal cord lesions. The agency model contained no persons who were injured at $\mathrm{C} 1-2 ; 11$ were injured 
at $\mathrm{C} 3-4$; and 18 were injured at $\mathrm{C} 4-5$. For those in the independent living model, eight were injured at $\mathrm{C} 1-2 ; 15$ at $\mathrm{C} 3-4$; and 19 at $\mathrm{C} 4-5$. Each person who used a ventilator was dependent on it $24-\mathrm{h}$ per day.

\section{Outcome variables (Table 2)}

For PASI, there was a significant variation between models using ANOVA. The mean PASI score for persons receiving their care through agencies was 50.67; for those in the independent living model, the mean was 70 . Significant differences were also evident in the level of satisfaction regarding cost of care and availability of personal care attendants. A higher PASI score is associated with greater satisfaction with care giving, more hours of paid care, more years since onset of disability, higher income, and less money spent on care.

On ANOVA, differences in the mean composite scores of PIP were significant. The mean PIP score for persons using agency care was 157.17; for those in the independent living model, the mean was 164.24. Thus, it would seem that persons now in the independent living model have a more internally-driven style. It is not known whether this existed prior to admission to Craig Hospital or whether it developed as a result of Craig Hospital's philosophy, which emphasizes internal locus of control.

LSI-A scores were not significantly different between models. Differences in life satisfaction for persons who had high SCI as compared to remembered pre-injury life satisfaction was presumably so large that this test did not adequately describe differences.

For RAND, using ANOVA, significant differences were seen between models, with persons in the independent living model experiencing a higher level of health. On CHART, analysis of variance revealed no significant differences between models.

\section{Discussion of findings}

In regard to costs, the least amount spent for care per day was $\$ 38$ and the highest was $\$ 798$. The mean cost per diem was $\$ 189$ for those using agencies and $\$ 170$ for those using non-agency care. This was determined by considering the total number of hours of care individuals were receiving, including the number of hours of unpaid care provided by family or friends (these hours were calculated at $\$ 7.50$ per hour since, theorectically, this would be the amount paid for non-agency attendants). Cost differential would have been much higher if the number of hours of paid care were equal between the models. Even using personal care attendants, the total cost of 24-h care through an agency would be $\$ 336$ per day versus $\$ 180$ for the same care without an agency. Thus, \$156 per day would be saved by not using an agency. The savings on a per-case basis for non-agency care would be $\$ 54.950$ per year for $24-\mathrm{h}$ care. If nurses were used, the savings would be substantially higher. Based on real agency costs in various geographical areas, the differential between using live-in personal care attendants, agency and non-agency based RN's is $\$ 317.460$ per case using the following dollar amounts: (a) $\$ 38.50$ per hour, agency RN care; (b) $\$ 28.00$ per hour, agency LPN care; (c) $\$ 14.00$ per hour, agency PCA care; (d) $\$ 24.00$ per hour, nonagency RN care; (e) $\$ 18.00$ per hour, non-agency LPN care; (f) $\$ 7.50$ per hour, non-agency PCA care; and (g) \$7.50 per hour for unpaid care.

Cost benefit analysis is important. Most persons with high SCI should have coverage 24-h per day whether it is paid or unpaid. There was no evidence in this study that the person who had 24-h skilled nursing through an agency had a better outcome. In fact, that person was the most dissatisfied respondent and had the highest number of hospital days during the preceding 6 months.

Table 2 Analysis of group outcomes

\begin{tabular}{lcc}
\hline Health outcome & Agency-provider model $(\mathrm{n}=29)$ & Self-managed model $(\mathrm{n}=42)$ \\
\hline RAND-36 Scores & & 1898.9 \\
$\quad$ Measure of recent health ${ }^{\mathrm{a}}$ & 1759.7 & 383.3 \\
Role limits due to physical health & 344.8 & $17.6(7$ persons $)$ \\
\% with one or more bladder, skin, and/or & $17.2(5$ persons $)$ & 19 (8 persons $)$ \\
$\quad$ upper respiratory problems & & 3.6 days \\
\% Hospitalized in last 6 months & 91 persons $)$ & 70.0 \\
Mean length of hospitalization & 6.89 days & 164.2 \\
Psycholsocial outcomes & & 9.3 \\
Mean PASI score & 50.7 & 345.8 \\
Mean PIP score & 157.2 & 9.4 \\
Mean LISA-A score & 350.8 & \\
Mean CHART score & &
\end{tabular}

${ }^{\mathrm{a}} P<0.01$ 


\section{Multivariate analysis (Table 3)}

Multivariate analysis supported the univariate hypothesis that the model of care-giving itself accounts for differences in health status on RAND; differences in quality of life and satisfaction with care-giving on the PASI and differences in locus of control on PIP.

In regard to Rand, $19 \%$ of the variation was explained by care model itself and by total medical problems; when eight demograhpic variables were entered into the regression, only care model remained. Variables no longer remaining were: current age; age at the time of injury; years since onset of disability; ratio of paid hours to total hours of care; level of education; and number of hospital days versus no hospital days. If an individual with high SCI received care through an agency he/she generally had a lower mean Rand score than if care had been received through the independent living model.

In a multiple regression with PASI as the dependent variable, the care model was entered on step one and education on step two in a list of eight independent variables. Fifty-five percent of the variation in PASI was explained by model. Another multiple regression was completed with PASI as the dependent variable. Days in the hospital, hours of paid care, hours of involvement per week, years since onset of disability, total income, care model, PIP score and total dollars spent were entered in a step-wise fashion. Again, 55\% of the variation was explained by model alone. Both model and income were left in the equation. Thus, care model was the strongest explanatory variable for differences in PASI. Persons in the independent living model had much higher PASI scores. Income made up approximately $3 \%$ of the explanatory variance.

On multiple regression with PIP as the dependent variable, independent variables included model, current age, age at onset of disability, years since onset, income, ratio of paid care to total hours of care, education, total medical problems and days in the hospital. In this regression $7 \%$ of the variation in personal independence score was explained by model.

\section{Conclusions}

A primary finding was that persons who were not using agencies realized a lower cost of care, better health status, and greater life satisfaction than those who were using agencies. Information in this study may lead to changes in economic decisions in regard to long-term care for individuals with any significant disability as well as for those with high SCI. The medical status of individuals in this study was excellent. Re-hospitalization days were few; a vast majority of persons reported no hospital days in the preceding 6 months.

Participants' responses to 'quality of life' and 'satisfaction with care' questions were positive. Quality of life seemed to be good for the majority of respondents. Individuals studied were active and remained out of bed most of the day; they left their residences several times per week and had numerous contacts with friends and family.

There are many unanswered questions regarding long-term planning for persons with high spinal cord injuries. It may not be practical for care-givers to work on a one-to-one basis. Group apartment buildings and group living settings may need to be developed for cost-effective shared care-giving. If this country is going to provide health indemnity coverage to all Americans and depend increasingly on a managed care model, we cannot afford to exclude efficient and rational long-term care.

Economic savings would result from the development of a national assistance program. ${ }^{15}$ These savings would include income tax contributions from persons who would be able to be gainfully employed if they had a personal care assistant, increased income tax contributions from family members of persons with disabilities who could be employed if they were not caring for a family member and reduced need for emergency room and hospital care for persons with disabilities who have more personal care assistance.

Positive health outcomes and cost containment are not mutually exclusive goals. This is particularly relevant as our society looks to reform its health care system. If a service design model with consumer input

Table 3 Analysis of costs of care

\begin{tabular}{lcccc}
\hline \multicolumn{1}{c}{ Type of care } & \multicolumn{2}{c}{ Agency-provider } & Model $(\mathrm{n}=29)$ & $\begin{array}{c}\text { Self-managed } \\
\text { Average daily cost }\end{array}$ \\
Average hours & Average hours & Averaly cost \\
\hline Paid skilled care (RN or LPN) & 1.6 & $\$ 47$ & 1.5 & $\$ 32$ \\
Paid PSA & 6.5 & $\$ 104$ & 13.0 & $\$ 97$ \\
Total: paid care & 8.1 & $\$ 151$ & 14.5 & $\$ 129$ \\
Unpaid PSA care & 7.7 & $\$ 58$ & 18.8 & $\$ 32$ \\
Total: paid + unpaid care & 15.8 & $\$ 209$ & - & $\$ 161$ \\
Average: annual costs & - & $\$ 76,285$ & $\$ 58,765$ \\
\hline
\end{tabular}

When subject was able to provide actual number of hours of paid care, but did not know the precise dollar amount, the following estimates of prevailing community hourly rates were utilized: Agency provided care: RN \$38.50; LPN \$28.00; PSA $\$ 14.00$. Self-hired care: RN \$24.00; LPN \$18.00; PSA \$7.50. All unpaid care was valued at \$7.50/h 
could be implemented, persons with severe, disabling conditions might have a higher quality of life and therefore be healthier and more productive. Although no long-term policy regarding personal care assistance will be perfect and care must be determined on a caseby-case basis, it would be appropriate to develop a national personal assistance services program which would enable these individuals to return to society as active participants.

\section{References}

1 Parsons T. On Institutions and Social Evolution. University of Chicago Press, Chicago, Il 1951, pp 235-254.

2 DeJong G, Brannon RW, Batavia AI. Financing, Health and Personal Care, Aging with Spinal Cord Injury, Demos New York, 1993.

3 Litvak S, Zukas H, Heumann JE. Attending to America: personal assistance for independent living: a survey of attendent programs in the United States for people of all ages with disabilities. World Institute on Disabilities, 1987.

4 Nosek MA, Quan H, Potter C. Personal Asisstance Satisfaction Index: An Assessment Tool for Individuals with Severe Disabilities. Houston: ILRU, unpublished article.

5 Nosek MA, Fuhrer MJ. Independence among people with disabilities I, a heuristic model. Rehabilitation Counseling Bulletin, September 1992, 36: 6-20.

6 Nosek MA, Fuhrer MJ, Holland CA. Independent among people with disabilities II, personal independence profile. Rehabilitation Counseling Bulletin, 1992; 36: 21 - 36.

7 Nosek MA, Fuhrer MJ, Rintala DM, Hart KA. The Use of Personal Assistance Services by Persons with Spinal Cord Injury. The Institute of Rehabilitation and Research Houston, 1992.

8 Litvak S. Overview of personal assistance services. Disabilities Study Quarterly. Fall 1991; 11: 1 - 4.

9 Treishmann RB. Spinal Cord Injuries: Psychological, Social and Vocational Rehabilitation, 2nd Ed., Demos Publications, New York, 1988.
10 Young J, Burns PE, Wilt JA. Medical charges incurred by the spinal cord injured during the first six years following injury. Spinal Cord Injury August 1992; $122-126$.

11 Sipski ML, Hendler S, DeLisa JA. Rehabilitation of patients with spinal cord disease. Neurologic Clinics August 1991; 9: 705-725.

12 Batavia AI, DeJong G, McKnew LB. Toward a national persona assistance program: the independent living model of long-term care for persons with disabilities. Journal of Health, Policies, Policy and Law 1991; 16: 523 - 545.

13 DeJong G, Batavia A, McKnew L. The independent living model of personal assistance in national long term care policy. Generations Winter 1992, 89-95.

14 Yoshida KK. Life reconstruction among individuals with spinal cord injury: a sociological analysis. Ph.D. thesis: University of Toronto, 1991.

15 Whiteneck GG et al. Mortailty and psychosocial outcomes of persons spinal cord injured more than twenty years ago. Paraplegia.

16 Whiteneck GG et al. Aging with Spinal Cord Injury, Demos Publications: New York, NY, 1993.

17 DeVivo MJ, Black KJ, Stover SL. Causes of death during the first twelve years of spinal cord injury. Archives of Physical Medicine and Rehabilitation March 1993, 74: 248 - 253.

18 Mackelprang RW, Hepworth DH. Ecological factors in rehabilitation of patients with severe spinal cord injuries. Social Work in Health Care 1987; 13: 23 - 28.

19 Ragnarsson K, Lammertse D. Rehabilitation in spinal cord disorders, 2 anatomy orthogenesis and research for neurologic recovery. Archives of Physical Medicine and Rehabilitation, March 1991; (72): $297-297$.

20 DeVivo MJ, Richards JS. Community reintegration and quality of life following spinal cord injury. Paraplegia 1991, 39-43.

21 Closson JB et al. Rehabilitation in spinal cord disorders, comprehensive management of spinal cord injury. Archives of Physical Medicine and Rehabilitation 1991; 72: $272-278$.

22 White LJ. The adjustment process of the spinal cord injured: case study reports. Ph.D. dissertation 1983: Oklahoma State University.

23 Meyers AR et al. Rehospitalization and spinal cord injury: cross-sectional survey of adults living independently. Archives of Physical Medicine and Rehabilitation October, 1985; 66: $704-$ 707. 